\title{
Androgen Receptor Splice Variant 3
}

National Cancer Institute

\section{Source}

National Cancer Institute. Androgen Receptor Splice Variant 3. NCI Thesaurus. Code C128292.

Androgen receptor protein that is comprised of the amino acids encoded by exons 1-3 and those encoded by cryptic exon 3 (CE3) of the human AR gene. This variant protein contains nuclear receptor transcriptional activation and DNA binding domains and is missing the hinge region and the nuclear receptor ligand binding and activation function2 domains. Expression of this variant is associated with both a constitutively active, gainof-function phenotype and prostate cancer. 